\title{
LA EFICACIA DE LOS ORGANISMOS DE CONTROL DE ETICA PÚBLICA Y ANTICORRUPCIÓN
}

\author{
EFFECTIVENESS OF BODIES OF PUBLIC CONTROL OF ETHICS AND \\ CORRUPTION
}

\author{
Alfonso Buteler \\ Universidad Nacional de Córdoba - Córdoba - Argentina
}

RESUMEN:Este artículo analizó la temática de la corrupción procurando destacar algunos datos empíricos relevantes, teniendo en cuenta siempre que la falta de ética trae corrupción. $O$ artículo se dividió en tres partes, en primer un enfoque ético, después el control efectuado por dos organismos especializados en materia de corrupción y de ética pública como son la Fiscalía de Investigaciones Administrativas y la Oficina Anticorrupción a los fines de explicar sus competencias y ámbitos de actuación. Por último, realizaremos algunas reflexiones finales a modo de conclusión.

Palabras - clave: corrupción, ética; control.

RESUMO: Este artigo analisou a temática da corrupção procurando destacar alguns dados empíricos relevantes, tendoemcontasempre que a falta de ética trazcorrupção. $O$ artigo se dividiuemtrês partes, emprimeiro lugar um enfoque ético, depois o controle efetuado por dois organismos especializados emmatéria de corrupção e de ética pública como são a Fiscalía de Investigaciones Administrativas e a Oficina Anticorrupcióncom o fim de explicar suascompetências e âmbitos de atuação. Por último, realizaremos as reflexõesfinais.

Palavras-chave: corrupção; ética; controle.

Revista do Direito da UNISC, Santa Cruz do Sul, v.1, n. 45, p. 128-144, jan. - abri. 2015. 


\section{INTRODUCCIÓN}

El trabajo se dividirá en tres partes. En primer término, efectuaremos una breve introducción sobre la temática de la corrupción procurando destacar algunos datos empíricos relevantes, teniendo en cuenta siempre que la falta de ética trae corrupción (CORTES, 2005).

Luego, abordaremos, específicamente, el control efectuado por dos organismos especializados en materia de corrupción y de ética pública como son la Fiscalía de Investigaciones Administrativas y la Oficina Anticorrupción a los fines de explicar sus competencias y ámbitos de actuación.Por último,realizaremos algunas reflexiones finales a modo de conclusión.

\section{APROXIMACIÓN AL TEMA}

La corrupción, como desnaturalización del poder (ARAÑA, 2003), constituye una preocupación mundial que ha motivado su regulación tanto en el ámbito nacional, comparado y supranacional (www.cienciaspenales.net).En este último plano se ha dictado, la Convención Interamericana en Contra de la Corrupcióny la Convención de NacionesUnidassobre el mismo tópico, a las que han adherido un sinnúmero de Estados.

No puede soslayarse que cualquier enfoque que se haga de la corrupción debe ser de carácter multidisciplinario y no meramente jurídico, pues sus causas son multívocas, aunque compartimos la postura de González Pérez, cuando señala que la corrupción es el producto de la degradación de los valores morales(PEREZ, 2011), en virtud del triunfo del materialismo exacerbado, el relativismo y el hedonismo.

Es que, en el mundo actual se pone el acento en lo que uno tiene y no en lo que uno es (ARAÑA, 2004) y el relativismo extremo, por otra parte, hace que los juicios de valor siempre dependan delavara del juzgador, habida cuentaque de acuerdo a esta concepción, no hay nada que pueda catalogarse de correcto de una manera apriorística y ninguna persona tiene autoridad para hacerlo. El trasplante de esos razonamientos al campo de la ética nos impone el subjetivismo y nos obliga a descartar teorías de tipo objetivo.

Revista do Direito da UNISC, Santa Cruz do Sul, v.1, n. 45, p. 128-144, jan. - abri. 2015. 
En ese marco global,algunos funcionarios o empleados públicos ven a la función estatal como la oportunidad para beneficiarse a sí mismo, a sus familiares, a un partido político, etc.;su actuar no está ya incardinado a alcanzar el interés de la comunidad sino el propio. A partir de ese panorama, esas personas no se sienten como servidores que sufren ante las carencias de los ciudadanos sino que éstas le son indiferentes ya que han perdido la sensibilidad y por ende, la capacidad de ver personas y problemas en los expedientes administrativos.

Sin embargo y mas allá de esas consideraciones que exceden -con creces- el objeto de este trabajo, entendemos en que el Derecho puede hacer una gran contribución -sobre todo desde el punto de vista preventivo-para resolver el problema de la corrupción y de la falta de conductas éticas, estableciendo reglas claras y precisas, tanto de actuación como de contralor que permitan disminuir los efectos nocivos de este mal (VANOSSI). Pues, como lo ha apuntado Mairal, "cuando el Derecho está presente la corrupción disminuye; cuando el Derecho desaparece surgen otros factores que inciden en la decisión pública. La corrupción es el mas importantes de esos otros factores" (MAIRAL, 2007, p. 239).

Ahora bien, la situación que se presenta en cuanto a los índices de corrupción difiere de acuerdo al grado de desarrollo de una sociedad. Por lo general, en los países mas avanzados la corrupción se presenta a través de actos aislados y se concentra en los cargos más altos (ya que allí los controles son más difíciles, existen mayores intereses comprometidos y redes de interés que los protegen) y es baja en los estratos públicos inferiores. Hay una cultura general de respeto a las reglas y los organismos de control actúan con eficacia detectando y castigando los actos de corrupción (OCAMPO, 1993). En los países en vías de desarrollado, en cambio, la corrupción impregna todo el Estado (GRONDONA, 1993) dando lugar a un sistema de corrupción "institucionalizada" cuyas características según Araña (2004, p. 109) son las siguientes:

1) La burocracia posee criterios éticos externos que se contradicen con la práctica administrativa interna.

2) La praxis interna administrativa anima la omisión de los criterios éticos que se predican hacia el exterior.

Revista do Direito da UNISC, Santa Cruz do Sul, v.1, n. 45, p. 128-144, jan. - abri. 2015. 
3) Los funcionarios que se distinguen por su honestidad e imparcialidad son una excepción y deben renunciar a los beneficios de una actuación corrupta generalizada.

4) Los funcionarios corruptos, que son mayoría, son protegidos y cuando se los descubre se los trata con indulgencia mientras que los denunciantes son víctimas de persecución.

5) Los funcionarios honestos encuentran dificultades para desarrollar su labor profesional dentro de la esfera pública.

6) Los encargados de perseguir la corrupción raramente actúan y, cuando lo hacen, disculpan cualquier incidente como un hecho aislado.

7) Se produce la ausencia de la idea de servicio público. Los funcionarios contemplan al trabajo administrativo como una oportunidad para exportarlo en beneficio propio.

8) La corrupción crece allí donde los ciudadanos no se identifican con los intereses colectivos y donde las autoridades se distancian del pueblo.

9) Ausencia de virtudes cívicas. En estos países es más importante la ganancia personal que colaborar en la gestión de intereses colectivos. En general, se detecta una falta de ciudadanos con fuerza moral para sobreponerse a estas situaciones.

Ya en lo que hace a nuestro país, Gordillo (1997) ha destacado la presencia de un sistema paralelo de corrupción. Mairal, por su lado,entiende que en la República Argentina existe un sistema legal, hecho formal y expresamente para favorecer la corrupción (MAIRAL, 2007).

\section{ALGUNOS DATOS EMPIRICOS RELEVANTES}

1) En primer lugar debe señalarse que conforme a los datos empíricos analizados en los últimos años la República Argentina se encuentra entre los países con mayores niveles de corrupción del mundo ubicándoselo, por lo general, por encima del puesto número cien en nivel de trasparencia (www.transparency.org).

2) Una investigación de la Universidad de Harvard ha demostrado la relación existente entre corrupción e igualdad. Los países en donde hay más desigualdad social se presentan un mayor índice de corrupción. A partir de esa ecuación puede colegirse que la desigualdad facilita la corrupción y la corrupción aumenta la desigualdad en una relación de uno a cinco (un punto de corrupción cinco puntos de desigualdad social, aproximadamente) (KLIKSBERG, 2014).

Revista do Direito da UNISC, Santa Cruz do Sul, v.1, n. 45, p. 128-144, jan. - abri. 2015. 
3) El costo social de la corrupción en nuestro país desde el regreso de la democracia en 1983 ha sido estimado en la suma de diez mil millones de pesos (www.acij.org.ar).

4) Un relevamiento realizado por el Centro de Investigaciones y Prevención de la Criminalidad ha revelado que desde la democracia se promovieron 750 causas judiciales vinculadas a la corrupción y solo en de tres de ellas hubo condenas. Según ese informe, el promedio de duración de causas judicial en donde se investigan actos de corrupción es de catorce años, contados desde la fecha en que se radica la denuncia hasta su finalización (www.acij.org.ar), lo cual ubica a esas causas cerca de los plazos de prescripción.

5) Se ha detectado, también, que los países que poseen leyes de acceso a la información pública tienen un nivel mas bajo de corrupción. Cabe destacar que en nuestro país, a nivel federal, solo regula la materia el Decreto 1172/03 de aplicación en el ámbito del Poder Ejecutivo Nacional, es decir, que carecemos de una ley aplicable a todo el Estado federal.

No puede pasarse por alto, con relación a este aspecto que el concepto de acceso a la información pública que se está utilizando en el derecho comparado no es ya solamente el clásico, es decir, el que faculta a los ciudadanos y extranjeros a acceder a la información pública que posea el Estado o los particulares obligados, sino que se trata de un concepto nuevo: el de información pública positiva, entendida como la obligación estatal de poner en conocimiento de la ciudadanía -por motu proprio o por imperio legal- la información pública.

Según este nuevo paradigma, no basta con que el Estado permita el acceso a la información sino que se encuentra obligado por imposición normativa-en la medida en que así se establezca- a poner a disposición de los ciudadanos -principalmente a través de medios informáticos- toda la información "mínima" que se considere útil en un sistema democrático y trasparente (GUICHOT, 2003), la cual debe ir aumentando gradualmente.

Así, en la actualidad, la presencia del ciudadano en la "arena pública" (CASSESE, 2005)permite la fiscalización de las decisiones estatales y el conocimiento de las mismas evitando, de ese modo, el oscurantismo

Revista do Direito da UNISC, Santa Cruz do Sul, v.1, n. 45, p. 128-144, jan. - abri. 2015. 
estatal,posibilitando el control de la corrupción estatal y el desempeño de los funcionarios dentro de los márgenes previstos en la Ley de Ética Pública. Por tales razones, la $\mathrm{CICC}^{1}$ y la $\mathrm{CNUCC}^{2}$, alguna normativa en el derechocomparado ${ }^{3}$ y el derecho comunitario europeo ${ }^{4}$ se han hecho eco de la

\footnotetext{
${ }^{1}$ Aprobada por Ley 24.759, B.O. 19/01/1997. Dicho instrumento prevé en el art. 10 que "Habida cuenta de la necesidad de combatir la corrupción, cada Estado Parte, de conformidad con los principios fundamentales de su derecho interno, adoptará las medidas que sean necesarias para aumentar la transparencia en su administración pública, incluso en lo relativo a su organización, funcionamiento y procesos de adopción de decisiones, cuando proceda. Esas medidas podrán incluir, entre otras cosas: a) La instauración de procedimientos 0 reglamentaciones que permitan al público en general obtener, cuando proceda, información sobre la organización, el funcionamiento y los procesos de adopción de decisiones de su administración pública y, con el debido respeto a la protección de la intimidad y de los datos personales, sobre las decisiones y actos jurídicos que incumban al público; b)La simplificación de los procedimientos administrativos, cuando proceda, a fin de facilitar el acceso del público a las autoridades encargadas de la adopción de decisiones; y c) La publicación de información, lo que podrá incluir informes periódicos sobre los riesgos de corrupción en su administración pública".

Por otra parte, el art. 13 dispone que "Cada Estado Parte adoptará medidas adecuadas, dentro de los medios de que disponga y de conformidad con los principios fundamentales de su derecho interno, para fomentar la participación activa de personas y grupos que no pertenezcan al sector público, como la sociedad civil, las organizaciones no gubernamentales y las organizaciones con base en la comunidad, en la prevención y la lucha contra la corrupción, y para sensibilizar a la opinión pública con respecto a la existencia, las causas y la gravedad de la corrupción, así como a la amenaza que ésta representa. Esa participación debería reforzarse con medidas como las siguientes: a) Aumentar la transparencia y promover la contribución de la ciudadanía a los procesos de adopción de decisiones; b) Garantizar el acceso eficaz del público a la información; c) Realizar actividades de información pública para fomentar la intransigencia con la corrupción, así como programas de educación pública, incluidos programas escolares y universitarios; d) Respetar, promover y proteger la libertad de buscar, recibir, publicar y difundir información relativa a la corrupción".

${ }^{2}$ Aprobada por Ley 26.097, B.O., 09/06/06.

${ }^{3}$ En tal orden de ideas, el art. 5 de la Ley 18.381 de Uruguay señala que "Los sujetos obligados deberán prever la adecuada organización, sistematización y disponibilidad de la información en su poder, asegurando un amplio y fácil acceso a los interesados. Los organismos públicos, sean o no estatales, deberán difundir en forma permanente, a través de sus sitios web u otros medios que el órgano de control determine, la siguiente información mínima: a) Su estructura orgánica; b) Las facultades de cada unidad administrativa; c) La estructura de remuneraciones por categoría escalafonaria, funciones de los cargos y sistema de compensación; d) Información sobre presupuesto asignado, su ejecución, con los resultados de las auditorías que en cada caso corresponda; e) Concesiones, licitaciones, permisos o autorizaciones otorgadas, especificando los titulares o beneficiarios de éstos; f) Toda información estadística de interés general, de acuerdo a los fines de cada organismo y g) Mecanismos de participación ciudadana, en especial domicilio y unidad a la que deben dirigirse las solicitudes para obtener información".
}

Por su parte, en Panamá el art. 9 de la Ley de Transparencia en la Gestión Publica y Habeas Data (Ley 6/2002) establece que "En atención al principio de publicidad, las instituciones del Estado están obligadas a tener disponible en forma impresa, en sus respectivos sitios en Internet y a publicar periódicamente, información actualizada respecto de los temas, documentos y políticas que a continuación se detallan: 1 . El reglamento interno actualizado de la institución. 2. Las políticas generales de la institución, que formen parte de su plan estratégico. 3. Los manuales de procedimientos internos de la institución. 4. La descripción de la estructura organizativa de la institución. 5. La ubicación de documentos por categorías, registros y archivos de la institución, y el funcionario responsable de éstos. 6 . La descripción de

Revista do Direito da UNISC, Santa Cruz do Sul, v.1, n. 45, p. 128-144, jan. - abri. 2015. 
cuestión al imponer a los Estados Partesel deber de instaurar en los sistemas internos mecanismos que permitan el desenvolvimiento del derecho de acceso a la información pública.

\section{LAS EXIGENCIAS INTERNACIONALES SOBRE LOS ÓRGANOS DE CONTROL DE LA CORRUPCIÓN Y LA ÉTICA PÚBLICA}

Ya en lo que hace específicamente a los órganos de control de la corrupción, la CICC,ha establecido pautas claras en el tema que nos ocupa, las cuales deben ser tenidas en cuenta por las autoridades locales de los países miembros bajo pena de responsabilidad internacional, pues sus preceptos son directamente operativos (MANFRONI, 2001), salvo en materia penal (GORDILLO, 1993).

En tal sentido, la CICC: a) Hace hincapié en el carácter preventivo del control; b) Impone la obligación de crear órganos de control superior con el fin de desarrollar mecanismos modernos para prevenir detectar sancionar y erradicar las prácticas corruptas (art. III 9) y c) Impone a los Estados el establecimiento de sistemas adecuados para recaudación y el control de los ingresos del Estado que impidan la corrupción. (art. Illinc 6)

También,la CNUCC contiene disposiciones específicas con relación al control estatal de esa materia. Ese instrumento supranacional impone a los Estados parte la obligación de:

a) Realizar una evaluación periódica para detectar si los instrumentos jurídicos y administrativos utilizados en el país para combatir la corrupción son adecuados.

los formularios y reglas de procedimiento para obtener información de la institución y dónde pueden ser obtenidos. Las instituciones públicas que tienen páginas electrónicas, además de los boletines, estarán obligadas a publicar a través de Internet la información que obliga la presente Ley. La Contraloría General de la República deberá publicar un informe sobre la ejecución presupuestaria, a más tardar dentro de los treinta días posteriores a dicha ejecución. El Ministerio de Economía y Finanzas deberá publicar un informe sobre la ejecución presupuestaria, a más tardar dentro de los treinta días posteriores a tal ejecución".

Por su parte, la Constitución de México en su art. 6ํㅡ, luego de consagrar el derecho de acceso a la información y proteger su ejercicio, señala en el punto $V$ que "Los sujetos obligados deberán preservar sus documentos en archivos administrativos actualizados y publicarán a través de los medios electrónicos disponibles, la información completa y actualizada sobre sus indicadores de gestión y el ejercicio de los recursos públicos".

${ }^{4}$ Vgr. En el ámbito de la Unión Europea la Recomendación del Comité de Ministros del 21 de febrero de 2002 sobre acceso a la información oficial.

Revista do Direito da UNISC, Santa Cruz do Sul, v.1, n. 45, p. 128-144, jan. - abri. 2015. 
b) Garantizar la existencia de órganos encargados de prevenir la corrupción y de otorgarles la independencia necesaria, para que puedan desempeñar sus funciones de manera eficaz y sin ninguna influencia indebida. Deben proporcionárseles los recursos materiales y el personal especializado que sean necesarios, así como la capacitación que dicho personal pueda requerir para el desempeño de sus funciones. (art. $6^{\circ}$ )

c) Adoptar las medidas que sean necesarias, para alentar la cooperación entre, por un lado, organismos públicos de cada Estado Parte, así como sus funcionarios públicos, y, por otro, sus organismos encargados de investigar y enjuiciar los delitos. (art. 38)

\section{LOS ORGANOS DE CONTROL DE LA CORRUPCION}

\section{A) Pautas que deben guiar el control público de la corrupción:}

1) Para que los métodos de fiscalización sean eficientes debe existir un intercambio permanente de información entre los organismos de control público y una aceitada coordinación entre los mismos, a fin de lograr la optimización de los resultados que se obtengan en el ejercicio de sus funciones (IVANEGA, 1999).

2) Deben simplificarse los procedimientos ante la administración pública (IVANEGA, 2011) ya que, en muchas ocasiones, crean la oportunidad para que los funcionarios sean corrompidos (VANOSSI). A esta idea puede contribuir, significativamente, la informatización de los trámites administrativos de modo tal de lograr sus despersonalización y por ende, la oportunidad para que se verifiquen actos reñidos con la ética pública; soluciones que han sido utilizadas exitosamente en Francia y en España.

3)La competencia de los órganos públicos de control de la corrupción y la ética pública no debe valorarse de una manera restrictiva sino amplia, de modo tal que permita su actuación;

4)Es inconveniente el otorgamiento de facultades a los organismos de control para que decidan a quien investiga y a quien no de acuerdo a criterios de oportunidad, mérito o conveniencia sino que deben reglarse los extremos que determinan la obligación de investigar.

Revista do Direito da UNISC, Santa Cruz do Sul, v.1, n. 45, p. 128-144, jan. - abri. 2015. 
5)La atribución de facultades discrecionales ${ }^{5}$,por lo general, facilita la concreción de prácticas corruptaspues, como señala Jaime Rodríguez - Arana Muñoz esas potestades en muchos casos se ejercen "en clave patrimonial y en beneficio personal en lugar de aspirar al servicio solidario de los intereses colectivos" (ARAÑA, 2004, p. 39). Según Mairal, en la República Argentina, ello es insuficiente ya que es muy común, incluso, que se pidan sobornos para aplicar la ley (MAIRAL, 2007) o que el funcionario honesto tenga miedo a resolver conforme a derecho por temor a ser sospechado como corrupto.

6)El ingreso a los órganos de control y los posteriores ascensos deben hacerse por concurso público de antecedentes y oposición y fortalecerse la carrera administrativa. De esta manera, se evita el nepotismo y se garantiza el mandato de idoneidad previsto en el art. 16 Carta Magna para los empleos públicos. $^{6}$

7) Debe promoverse el reconocimiento constitucional de los organismos de control de la corrupción de modo tal de evitar que por ley o decreto se limiten sus competencias o se los elimine como órganos de control.

\footnotetext{
${ }^{5}$ La Corte ha distinguido la actividad reglada de la administración pública del ejercicio de facultades discrecionales de la siguiente manera: "mientras en algunos supuestos el ordenamiento jurídico regula la actividad administrativa en todos sus aspectos -reemplazando así el criterio del órgano estatal al predeterminar qué es lo más conveniente para el interés público y reducir su actividad a la constatación del presupuesto fáctico definido por la norma en forma completa y la aplicación de la solución que la ley agotadoramente ha establecido (poderes reglados o de aplicación legal automática)-, en otras ocasiones el legislador autoriza a quien debe aplicar la norma en el caso concreto para que realice una estimación subjetiva que completará el cuadro legal y condicionará el ejercicio para ese supuesto de la potestad atribuida previamente o de su contenido particular al no imponerle, por anticipado, la conducta que debe necesariamente seguir (facultades o potestades de ejercicio discrecional)" (Fallos, 315:1361, consid. $6^{\circ}$, "Consejo de la Presidencia de la Delegación Bahía Blanca de la Asamblea Permanente por los derecho humanos").

${ }^{6}$ En tal sentido, la Declaración Universal de los Derechos Humanos en el art. 21 inc. $1^{\circ}$ señala que "Toda persona tiene el derecho de acceso, en condiciones de igualdad, a las funciones públicas de su país" exigencia que repite el art. 25 inc. c) del Pacto Internacional de Derecho Civiles y Políticos.

Por su lado, el art. 2 de la Convención Interamericana contra la Corrupción prescribe que los Estados Parte convienen en procurar la aplicación de medidas dentro de sus propios sistemas institucionales que tengan por objeto crear, mantener y fortalecer: "Sistemas para la contratación de funcionarios públicos y para la adquisición de bienes por parte del Estado que aseguren la publicidad, la equidad y eficiencia de tales sistemas".

En la misma línea, la CNUCC en su art. 9.1 señala que los Estado Parte, se comprometen a adoptar las medidas necesarias para establecer sistemas apropiados de contratación pública que se basen en la transparencia, la competencia y criterios objetivos de adopción de decisiones, que sean eficaces para prevenir la corrupción. Luego agrega que esos sistemas, deberán abordar, entre otras cosas:
}

Revista do Direito da UNISC, Santa Cruz do Sul, v.1, n. 45, p. 128-144, jan. - abri. 2015. 
8) Así, como el art. 42 de la C.N.permite la participación de los usuarios en los organismos de control de los servicios públicos debería normarse la participación de los ciudadanos en los organismos de control de la corrupción y la ética pública.

\section{B) La oficina anticorrupción}

De acuerdo a la ley 25.233 que le dio nacimiento,la Oficina Anticorrupción $(\mathrm{OA})$ se ubica en la esfera del Ministerio de Justicia de la Nación.Tiene a su cargo la elaboración y coordinación de programas de lucha contra la corrupción en el Sector Público Nacional ${ }^{7}$ o que tenga como principal fuente de recursos el aporte estatal y es la autoridad de aplicación de la Ley de Ética Pública ${ }^{8}$ y de la $\mathrm{CICC}^{9}$.

El art. 60 establece que la OAestará a cargo de un Fiscal de Control Administrativo, designado y removido por el Presidente de la Nación a propuesta del Ministro de Justicia.

Entre sus competencias previstas en el art. 2 se destacan:

1) La facultad de recibir denuncias que hicieran particulares 0 agentes públicos que se relacionen con su objeto e investigarlos si correspondiere;

2) Investigar preliminarmente a toda Institución o Asociación que tenga como principal fuente de recursos el aporte estatal, en caso de sospecha

\footnotetext{
${ }^{7}$ Al respecto el art. 8 de la Ley 24.156 (B.O. 29/10/1992) indica que el Sector Público Nacional está integrado por: a) Administración Nacional, conformada por la Administración Central y los Organismos Descentralizados, comprendiendo en estos últimos a las Instituciones de Seguridad Social; b) Empresas y Sociedades del Estado que abarca a las Empresas del Estado, las Sociedades del Estado, las Sociedades Anónimas con Participación Estatal Mayoritaria, las Sociedades de Economía Mixta y todas aquellas otras organizaciones empresariales donde el Estado nacional tenga participación mayoritaria en el capital o en la formación de las decisiones societarias; c) Entes Públicos excluidos expresamente de la Administración Nacional, que abarca a cualquier organización estatal no empresarial, con autarquía financiera, personalidad jurídica y patrimonio propio, donde el Estado nacional tenga el control mayoritario del patrimonio o de la formación de las decisiones, incluyendo aquellas entidades públicas no estatales donde el Estado nacional tenga el control de las decisiones; d) Fondos Fiduciarios integrados total o mayoritariamente con bienes y/o fondos del Estado nacional. Serán aplicables las normas de esta ley, en lo relativo a la rendición de cuentas de las organizaciones privadas a las que se hayan acordado subsidios o aportes y a las instituciones o fondos cuya administración, guarda o conservación está a cargo del Estado nacional a través de sus Jurisdicciones o Entidades.

${ }^{8}$ Ley 25.188 , B.O., 01/11/1999.

${ }^{9}$ Decreto 102/99, B.O., 29/12/1999.
}

Revista do Direito da UNISC, Santa Cruz do Sul, v.1, n. 45, p. 128-144, jan. - abri. 2015. 
razonable sobre irregularidades en la administración de los mencionados recursos;

3) Denunciar ante la justicia competente los hechos que como consecuencia de las investigaciones practicadas, pudieren constituir delitos;

4) Constituirse en parte querellante en los procesos en que se encuentre afectado el patrimonio del Estado. Adviértase que solo puede intervenir en causas penales en la calidad de querellante pero no tiene en su cabeza la posibilidad de llevar adelante la acción penal pues de lo contrario habría una injerencia del Poder Ejecutivo en el Ministerio Público, tal como lo entendió la Corte Suprema en el caso "Aslanian";

5) Llevar el registro de las declaraciones juradas de los agentes públicos;

El art. 3ำ, por su parte, sujeta el ejercicio de las principales funciones establecidas en el art. $2^{\circ}$ al hecho de que el Fiscal de Control Administrativo considere la cuestión de significación institucional, económica o sociallo cual pone de resalto para la doctrina la discrecionalidad que posee en dicha apreciación (ORGAZ, 2003).Como podrá advertirse, en esa regulación, es fundamental el principio de oportunidad, a partir de criterios de significación institucional (exceso de poder, desviación de los fines de un organismo, etc.), social (situaciones en las cuales el funcionamiento del organismo tiene un impacto apreciable en la población) y económica (cuestiones relativas a la eficiencia con la cual es administrado un organismo) (MASSONI, 2009).

En lo que respecta al aspecto adjetivo, una vez que se ha detectado una supuesta trasgresión,las actuaciones pasarán con dictamen fundado al Ministro de Justicia, a la Procuración del Tesoro de la Nación y al funcionario de mayor jerarquía administrativa de la repartición de que se trate. Esas actuaciones servirán de cabeza del sumario que deberá ser instruido por las autoridades correspondientes en donde la OA podrá ser tenida como parte acusadora con facultades de ofrecer, producir o incorporar pruebas, así como la de recurrir toda resolución adversa a sus pretensiones.

En nuestra opinión, el hecho de ser designado por el Presidente de la Nación y su ubicación jerárquica dentro del Ministerio de Justicia, ponen en evidencia una clara falla estructural y el incumplimiento de los estándares

Revista do Direito da UNISC, Santa Cruz do Sul, v.1, n. 45, p. 128-144, jan. - abri. 2015. 
establecidos por las convenciones internacionales a que aludimos mas arriba. Ello, en tanto, dicho organismo de control, no tiene garantizada su independencia, pues debe controlar a sus superiores y a quienes le asignan recursos. Es que, como lo recuerda Canda, es una regla básica en materia de control que el controlante no dependa del controlado (CANDA, 2003).

\section{C) Fiscalía de investigaciones administrativas}

La Fiscalía de Investigaciones Administrativas (FIA)forma parte delMinisterio Público Fiscal como órgano dependiente de la Procuración General de la Nación. Está integrada por el Fiscal Nacional de Investigaciones Administrativas y los demás magistrados que establece la Ley 21.383. En virtud de ubicación institucional al integrar un órgano extrapoder, tiene independencia con relación a los tres poderes estatales lo cual resulta fundamental en la medida en que su actividad es exógena a la de los investigados (CANDA, 2009).

Tiene como finalidad controlar la legalidad administrativa y en caso de detectar irregularidades, ordenar a través de un dictamen que es vinculante, la instrucción de sumarios administrativos o -en su caso- denunciar penalmente y participar en las causas con los alcances que analizaremos mas adelante.

La modificación de la ley 21.383 que permitía la remoción del Fiscal de Investigaciones Administrativas por un decreto del Poder Ejecutivo Nacional tal como ocurrió en el recordado caso"Molinas"10, ha sido un gran avance para lograr la independencia de este órgano de control. Es que en la actualidad la remoción dependerá de la decisión de un Tribunal de Enjuiciamiento que, a su vez, está sujeta al control judicial posterior.

También, es un aliciente que la designación de los miembros de la FIA se hagapor concurso de oposición y antecedentes. Empero, es criticable que la terna que resulte de ese proceso de selección deba ser elevada al Poder Ejecutivo Nacional por el Procurador General para que proponga uno de ellosal

\footnotetext{
${ }^{10}$ En ese caso, frente al cuestionamiento -por vía de amparo- contra la legitimidad de un decreto del P.E.N. por el cual se había resuelto separar de su cargo al Fiscal de Investigaciones Administrativas sin la realización de un sumario previo, la Corte Suprema rechazó la demanda.
}

Revista do Direito da UNISC, Santa Cruz do Sul, v.1, n. 45, p. 128-144, jan. - abri. 2015. 
Senado para su nombramiento. A su vez, es destacable que los integrantes de la FIA posean estabilidad en sus cargos mientras dure su buena conducta y hasta los 75 años.

Por su parte, el art. 45 de Ley Orgánica del Ministerio Público (LOMP) establece que dicha autoridad de contralor tiene como funciones las siguientes:

a) Promover la investigación de la conducta administrativa de los agentes integrantes de la administración nacional centralizada y descentralizada, y de las empresas, sociedades y todo otro ente en que el Estado tenga participación.

En caso de irregularidades pasará las actuaciones con dictamen fundado a la Procuración del Tesoro de la Nación o al funcionario de mayor jerarquía administrativa de la repartición de que se trate, las que servirán de cabeza del sumario que deberá ser instruido por las autoridades correspondientes y la FIA será tenida como parte acusadora, con iguales derechos a la sumariada, en especial, las facultades de ofrecer, producir e incorporar pruebas, así como la de recurrir toda resolución adversa a sus pretensiones.

b) Efectuar investigaciones en toda institución o asociación que tenga como principal fuente de recursos el aporte estatal, en caso de sospecha razonable sobre irregularidades en la inversión dada a los mencionados recursos.

c) Denunciar ante la justicia competente, los hechos que, como consecuencia de las investigaciones practicadas, sean considerados delitos. En tales casos, las investigaciones de la Fiscalía tendrán el valor de prevención sumaria. El ejercicio de la acción pública quedará a cargo de los fiscales competentes ante el tribunal donde quede radicada la denuncia con la intervención necesaria del FIA o de los magistrados que éste determine.

d) Tendrá intervención cuando en el curso de un proceso judicial en sede penal se efectúe imputación formal de delito contra un agente público por hechos vinculados con el ejercicio de su función, el juez de la causa deberá poner esta circunstancia en conocimiento de la Fiscalía de Investigaciones Administrativas.

Revista do Direito da UNISC, Santa Cruz do Sul, v.1, n. 45, p. 128-144, jan. - abri. 2015. 
e) Asimismo, para los casos en que los fiscales del fuero no estuvieren de acuerdo con la prosecución de la acción, podrá la FIA asumir en cualquier momento el ejercicio directo de la acción pública.

Como puede advertirse, la FIA es un organismo que reúne muchas de las competencias y facultades deseables para luchar en contra de la corrupción. Así, lo pone de resalto también la labor realizada por dicho organismo en los últimos años.

Sin embargo, a partir del dictado de la Resolución 147/08del Procurador General de la Nación (PGN) la situación que se presenta es diferente en tanto se han limitado notablemente las facultades de dicho organismo en la jurisdicción penal.En dicha resolución, el PGN -dictada según dicho funcionario para precisar funciones, prerrogativas y competencia de la FIA-sostiene que:

1) La FIA nunca fue concebida como una fiscalía penal temática, investida de la facultad de monopolizar la representación del Ministerio Público Fiscal en casos de corrupción. En contra de esa postura explicitada se ha manifestado Canda al sostener el carácter especifico de la FIA y de los magistrados que la componen por sobre los demás fiscales (CANDA, 2003).

2) En las causas iniciadas por denuncia de la FIAmientras se mantenga la investigación a cargo del fiscal de la causa, la FIA puede acceder al expediente y concertar cursos de acción con el fiscal pero siempre la representación es única y depende del fiscal a cargo.

3) Para que la FIA pueda ejercer directamente la acciónes necesario que previamente el fiscal de la causa haya exteriorizado un criterio contrario a la prosecución de la acción. (art. 45 inc. C de la LOMP) Los fiscales deben informar a la FIA cada vez que así lo decidan para que ésta pueda asumir la defensa.

Por nuestra parte destacamos, que esa inteligencia asignada a dicho precepto normativo se opone a la jurisprudencia de la Corte Suprema Nacional, habida cuenta que en la causa "Ríos" el Alto Tribunal admitió en el ejercicio directo de la acción pública por la FIA, aun ante la discrepancia del fiscal de la causa. Este criterio se repitió luego en "Caciatore” en 1988.

4) La FIA no puede intervenir en las medidas cautelares.

Revista do Direito da UNISC, Santa Cruz do Sul, v.1, n. 45, p. 128-144, jan. - abri. 2015. 
5) Cuando una causa haya sido iniciada por una vía distinta a la denuncia de la FIA los jueces se encuentran obligados a comunicar a aquella todos los casos en los que se halle imputado un funcionario público. En esos supuestos, también se debe garantizar la intervención judicial "necesaria" de la FIA pero siempre sujeto a la decisión del fiscal de la causa.

A partir de esa decisión de la PGN, el ejercicio de la acción penal directa por la FIA requiere de manera concurrente que la causa penal sea iniciada por ésta y que el fiscal federal tenga un criterio diferente al de dicho organismo de control en cuanto a seguir interviniendo en la causa.

Esa interpretación de las atribuciones de la FIA que propone la mentada resolución, si bien puede tener cierto respaldo normativo, violenta las prescripciones de las convenciones internacionales en cuanto obliga a cada Estado Parte a asegurar la independencia y a otorgarle las herramientas necesarias para que puedan hacer un eficaz control de la corrupción. No podemos hablar de un control eficaz de la corrupción si la FIA no tiene facultades judiciales concretas.

\section{REFLEXIONES FINALES}

Del análisis efectuado queda claro a nuestro entender que es necesaria una verdadera voluntad política de controlar la corrupción y de cumplir con las exigencias supranacionales estableciendo organismos de control independientes con facultades concretas y útiles. Solo de esa manera puede haber un control integral y eficiente de esta materia.

Creemos que, como lo señala Mairal, es necesario dejar de manejarnos con una linterna apuntando a unos pocos y prender la luz dentro de la administración (MAIRAL, 2007).

\section{REFERÊNCIAS}

ARANA, JaimeRodriguez.Ética, Poder y Estado. Buenos Aires, RAP, $2004 .$.

Revista do Direito da UNISC, Santa Cruz do Sul, v.1, n. 45, p. 128-144, jan. - abri. 2015. 
CANDA. Fabián O. Control de la Administración Pública, Administrativo, Legislativo y Judicial.2 ed. Jornadas Organizadas por Universidad Austral, Facultad de Derecho, Buenos Aires, Rap, 2009.

CANDA, Fabián Omar. La Fiscalía de Investigaciones Administrativas.EDA, 2003.

CASSESE. Sabino. La crisis del Estado, Buenos Aires: Lexis, Nexis, 2005.

CORTES, MaríaJeanneret de Perez. Ética y función pública. 2005.

GARCIA MEXIA, Pablo. Reflexiones al hilo de I Congreso Internacional de ética publica. Revista de Administración Publica española, 1993.

GONZALEZ PEREZ, Jesús. La Ética Pública. Revista Argentina delRégimen de laAdministración Pública, n. 283. 1995.

GORDILLO, Agustín. La administración paralela. 2 ed. Madrid:Civitas , 1997. . Tratado de Derecho administrativo.5 ed. Buenos Aires: Fundación de Derecho Administrativo, 1993.

GRONDONA, Mariano. La Corrupción. Buenos Aires: Planeta, 1993.

GUICHOT,Emilio. El nuevoderechoeuropeo de acceso a lainformación pública. Revista de laAdministración Pública española,n 160, 2003.

HUBER, Bárbara. La lucha contra lacorrupción desde una perspectiva supranacional. Revista Penal n. 11. Friburgo. Disponível em: $<$ www.cienciaspenales.net>. Aceso: 09 abri. 2014.

IVANEGA, Miriam M. Las entidades Fiscalizadoras Superiores y la lucha contra la corrupción. RAP, 1999.

.Reflexiones acerca de la ética y la función pública. RAP, Circular letter, n. 149, 2011.

KLIKSBERG, Bernardo. Corrupción. Mas allá de los

mitos. Disponível em: <www.el pais.com>. Acesso: 23 maio 2014.

MAIRAL, Héctor A. Lasraíceslegales de lacorrupción: o de cómoelderecho público fomenta lacorrupciónen lugar de combatirla. Buenos Aires: RAP, 2007.

MANFRONI, Carlos A. La convención interamericana contra la corrupción, anotada y comentada.2 ed. Buenos Aires: AbeledoPerrot, 2001.

MASSONI, José. La Oficina Nacional de Anticorrupción. In: AA.VV. Control de la Administración Pública, Administrativo, Legislativo y Judicial,Jornadas Organizadas por Universidad Austral, Buenos Aires: RAP,

Revista do Direito da UNISC, Santa Cruz do Sul, v.1, n. 45, p. 128-144, jan. - abri. 2015. 
2009.OCAMPO, Luis Moreno. La Corrupción. Buenos Aires: Planeta, 1993.ORGAZ, Jorge. El procedimiento de control de las irregularidades administrativas. Córdoba: Alveroni. 2003.PÉREZ HUALDE, Alejandro.

Instrumentos para un régimen jurídico de combate a la corrupción, La Ley, 20 jun. 2011.VANOSSI, Jorge R. Primera aproximación al enfoque jurídico de la corrupción. E.D. 149:745.

Revista do Direito da UNISC, Santa Cruz do Sul, v.1, n. 45, p. 128-144, jan. - abri. 2015. 